\title{
Effect of Fe (III) Speciation in the Polymeric Ferric Sulfate on the Treatment Performance of Surface Water Contaminated Slightly
}

\author{
Dan $\mathrm{LI}^{\mathrm{a}}$ and Yong KANG ${ }^{\mathrm{b},{ }^{*}}$
}

\author{
School of Chemical Engineering and Technology, Tianjin University, Tianjin 300350, China \\ a15222512355@163.com (D. Li), bykang@tju.edu.cn (Y. Kang)
}

Keywords: Polymeric ferric sulfate, Fe (III) species, Surface water, Humic acid.

\begin{abstract}
Fe-Ferron method was used to investigate the role of $\mathrm{Fe}(\mathrm{III})$ speciation of the polyferric sulfate (PFS) in coagulation-flocculation the process with surface water. The experiments results show that the $\mathrm{Fe}_{\mathrm{b}}$ components are dominant contents under a broad $\mathrm{pH}$ variation during the coagulation. The humic acid (HA) removal is found directly related to the aggregation of iron components in the water, the maximum removal of the HA occurs in the $\mathrm{pH}$ range from 7 to 8 , at which the changes of zeta potential explain that charge neutralization and the compression double electric layer are the main mechanisms of coagulation. The role of adsorption and sweeping by amorphous $\mathrm{Fe}(\mathrm{OH})_{3}$ that cannot be ignored in the treatment with surface water at the same time.
\end{abstract}

\section{Introduction}

Humic substances are the major components of natural organic matter (NOM) in the surface water, which are the precursors of disinfection by-products (DBPs) such as trihalomethanes (THMs) and haloacetates (HAAs)[1]. DBPs have been confirmed related to several types of cancer, so lots of advanced technologies including ozonation, ultrafiltration, photocatalysis, and anion exchange are adopted to remove NOM, among them, enhanced coagulation is considered to be the most convenient and economical one for minimizing DBPs[2].

PFS is a kind of pre-polymerized inorganic coagulants used to remove colloids, particles, and organics in the water. PFS is the intermediate product during the hydrolysis-aggregation-precipitation process of the iron, containing various poly-nuclear iron ions, such as $\mathrm{Fe}_{2}(\mathrm{OH})_{2}{ }^{4+}, \mathrm{Fe}_{3}(\mathrm{OH})_{4}{ }^{5+}[3]$. It is widely agreed that Fe (III) speciation is directly connected to the coagulation behavior of PFS, so many studies have tried to optimize iron species distribution by improving the preparation conditions [4-9], but there is limited work about the relationship between coagulation efficiency and transformation of iron species during the whole coagulation-flocculation process.

In this paper, Fe-Ferron method was taken to quantitatively characterize the Fe (III) species during the treatment with surface water, the effects of dosage and $\mathrm{pH}$ value were studied, the mechanisms of iron polymer species on the removal of HA were discussed at the same time.

\section{Materials and Methods}

\section{Coagulants and Test Water}

The PFS was prepared in the laboratory using $\mathrm{FeSO}_{4}, \mathrm{H}_{2} \mathrm{O}_{2}, \mathrm{H}_{2} \mathrm{SO}_{4}$ and deionized water, the content of total Fe and basicity of the liquid PFS were $15.04 \%(3.48 \mathrm{~mol} / \mathrm{L}$ as $\mathrm{Fe})$ and $20.14 \%$, respectively. The test water used in the experiments was slightly contaminated surface water (Table 1) collected from Qingnian Lake in Tianjin University in May.

Table 1 Characteristics of the surface water used in the experiments.

\begin{tabular}{cccccc}
\hline $\mathrm{T}\left({ }^{\circ} \mathrm{C}\right)$ & $\mathrm{pH}$ & $\begin{array}{c}\mathrm{DOC} \\
(\mathrm{mg} / \mathrm{L})\end{array}$ & $\begin{array}{c}\text { Turbidity } \\
(\mathrm{NTU})\end{array}$ & $\begin{array}{c}\mathrm{UV}_{254} \\
(/ \mathrm{cm})\end{array}$ & $\begin{array}{c}\text { SUVA } \\
\left(100 \times \mathrm{UV}_{254} / \mathrm{DOC}\right)\end{array}$ \\
\hline $23.5 \pm 2.0$ & $8.27 \pm 0.25$ & $19.85 \pm 0.05$ & $20.48 \pm 0.50$ & $0.1048 \pm 0.0005$ & $0.525 \pm 0.005$ \\
\hline
\end{tabular}




\section{Jar Tests}

Jar tests were conducted using a six-peddle stirrer at room temperature $\left(24 \pm 2^{\circ} \mathrm{C}\right)$. A total $250 \mathrm{~mL}$ volume of test water, previously adjusted to a desired $\mathrm{pH}$ value with $1 \mathrm{M} \mathrm{NaOH}$ and $\mathrm{HCl}$, was transferred into a 500mL beaker. Predesigned amount of PFS stock solution was injected under rapid stirring conditions. After being dosed, 30s of rapid mixing at 200rpm was applied, followed by 15 min of slow stirring at $30 \mathrm{rpm}$ and then 20 min for settling. After the completion, the supernatants samples were passed through a $0.45 \mu \mathrm{m}$ filter to measure $\mathrm{UV}_{254}$ and dissolved organic carbon (DOC), $\mathrm{UV}_{254}$ was analyzed with a UV/Vis analyzer (L6S, INESA, China) at 254nm. DOC was tested with a TOC Analyzer (TOC-L, Shimadzu, Japan). The removal of $U_{254}$ absorbance was used to evaluate the HA removal efficiency in this study. A small amount of sample was taken immediately to measure zeta potential using a microscopic electrophoresis apparatus (JS94H, Shanghai zhongchen digital technic apparatus Co. China) after $1 \mathrm{~min}$ rapid mix.

A parallel experiment was performed to investigate the adsorption ability for HA by iron precipitates. Certain amount of PFS stock solution was first added to $250 \mathrm{~mL}$ of tap water with the given $\mathrm{pH}$, the ionic strength of the solution was kept at $0.01 \mathrm{M}$ with $\mathrm{NaCl}$. After that, the stirring conditions were the similar with jar tests to generate iron flocs. After being settling, the total solution was filtered to get the precipitates, then the precipitates were dried to constant weight at $40^{\circ} \mathrm{C}$, and then distributed to the $250 \mathrm{~mL}$ of surface water respectively, and then, $15 \mathrm{~min}$ of slow mixing (30rpm) was conducted, followed by 20 min of settling. Finally, the supernatant was filtered to analyze the residual $\mathrm{UV}_{254}$ absorbance.

\section{Analysis of Fe (III) Species Distribution during Coagulation-Flocculation}

The measurement procedure of Fe (III) species by the Ferron reagent was performed as the previous reports $[10,11]$. A certain amount of water sample was taken from the beakers $2 \mathrm{~cm}$ below the water surface to analyze iron species with the UV/Vis analyzer at $600 \mathrm{~nm}$ as soon as every stirring step completed, the concentration of total $\mathrm{Fe}\left(\mathrm{Fe}_{\mathrm{T}}\right)$ was measured by the 1,10-phenanthroline spectrophotometry according to GB/T 5750.6-2006, monomeric and dimeric species $\left(\mathrm{Fe}_{\mathrm{a}}\right)$ can be determined from the $1 \mathrm{~min}$ absorbance reading, medium or reactive polymers $\left(\mathrm{Fe}_{\mathrm{b}}\right)$ were determined from $1 \mathrm{~min}$ to the $24 \mathrm{~h}$. Nucleated and precipitated species $\left(\mathrm{Fe}_{\mathrm{c}}\right)$ were calculated using the formula of $\mathrm{Fe}_{\mathrm{c}}=\mathrm{Fe}_{\mathrm{T}}-\mathrm{Fe}_{\mathrm{a}}-\mathrm{Fe}_{\mathrm{b}}$.

\section{Results and Discussion}

\section{Characterization of Fe (III) Species for PFS Stock Liquid (SL)}

As known to all, the solid coagulants must be dissolved to obtain a stock solution before being dosed. During this process, the $\mathrm{Fe}_{\mathrm{T}}$, the $\mathrm{pH}$ value, and other conditions will change, as well as the $\mathrm{Fe}$ (III) species, and these changes have a direct effect on the coagulation performance. Fig.1 presents the effect of maturing time on the iron species distribution of PFS after being diluted to the SL (1mol/L as $\mathrm{Fe}, \mathrm{pH}=1.94)$. The $\mathrm{Fe}_{\mathrm{a}}$ is the dominant content in the entire process. When PFS samples were initially diluted, the $\mathrm{pH}$ of SL rose slightly, indicating there was disintegration of the polymers, the hydroxyl bridge broke, resulting in hydroxide being released into the solution[12], so the $\mathrm{Fe}_{\mathrm{b}}$ and $\mathrm{Fe}_{\mathrm{c}}$ changed appreciably, eight hours later, the $\mathrm{Fe}_{\mathrm{b}}$ increased to a maximum value, about $36 \%$, soon after, a large part of the $\mathrm{Fe}_{\mathrm{b}}$ was converted to the $\mathrm{Fe}_{\mathrm{c}}$. Those changes above suggested a complex species transformation took place after being diluted. In the following 18 hours, small changes happened in the distribution of iron species of the SL.

\section{Effect of Dosage of the Coagulant on HA and DOC Removal}

Fig. 2 records the variation of residual $U_{254}$ absorbance and DOC at different dosages of PFS at the initial $\mathrm{pH} 8.27 \pm 0.25$. The $\mathrm{UV}_{254}$ absorbance and DOC decreased sharply first and reached the minimum values at $54 \mathrm{mg} \mathrm{Fe} / \mathrm{L}$, then the removal efficiency deteriorated with further increasing of the dose. The overdose of PFS would not improve the remove of $\mathrm{UV}_{254}$, but inhibited the coagulation 
performance. When the dosage of PFS reached $72 \mathrm{mg} \mathrm{Fe} / \mathrm{L}$, the residual $\mathrm{UV}_{254}$ was even higher than the initial one, which may be caused by the chromaticity induced by iron ions.

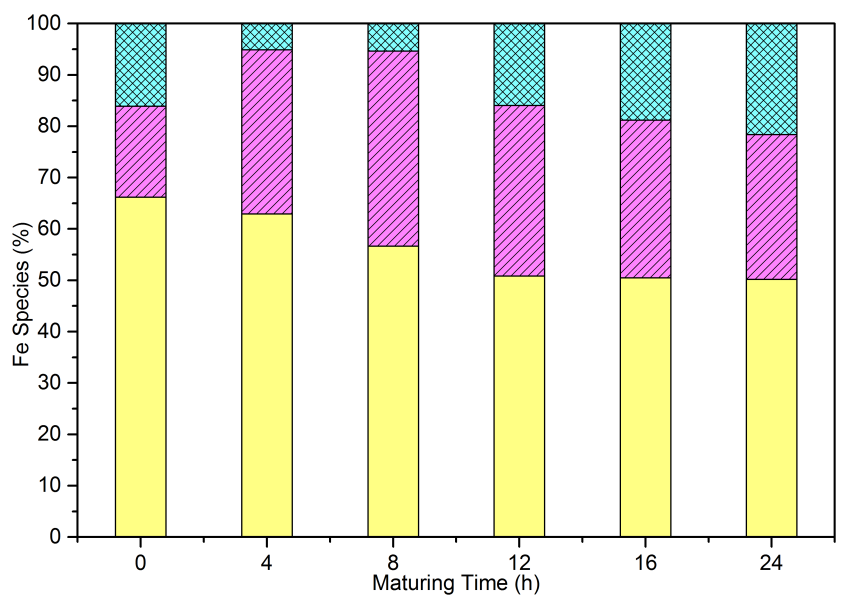

Fig. 1 Effect of the maturing time after being diluted on the iron species in SL.

$$
\mathrm{Fe}_{\mathrm{a}}(\mathrm{Q}), \mathrm{Fe}_{\mathrm{b}}(\mathrm{Q}), \mathrm{Fe}_{\mathrm{c}}(\mathrm{\square})
$$

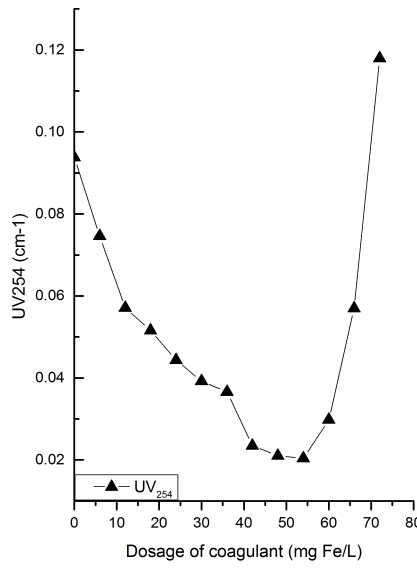

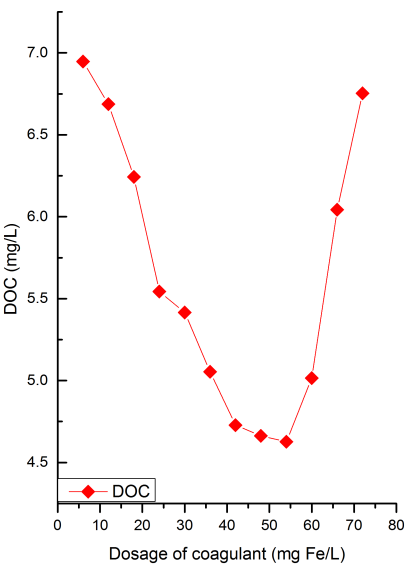

(b)

Fig. 2 Effect of the dose on the removal efficiencies of $U_{254}$ and DOC. (a) The residual $U^{254}$, (b) The residual DOC.

\section{Conversion of Fe (III) Species during Stirring under Different pH Values}

Fig. 3 shows the distribution of different iron species in the test water with $\mathrm{pH}$ ranging from 3.5 to 9.5. The coagulant dosage was of $54 \mathrm{mg} \mathrm{Fe} / \mathrm{L}$, which was confirmed to be the suitable value according to the Fig. 2. The distribution indicated that iron species were $\mathrm{pH}$ dependent, the monomers $\left(\mathrm{Fe}_{\mathrm{a}}\right)$ decreased sharply with the $\mathrm{pH}$ rising for all the three stages, whereas the $\mathrm{Fe}_{\mathrm{b}}$ rose and then declined after achieving the maximum point when the $\mathrm{pH}$ equal to 6.5-7.5, the $\mathrm{Fe}_{\mathrm{c}}$ increased gradually and dominated at the last stage. Compared with the iron speciation in the SL, as the coagulant being dosed, $\mathrm{Fe}_{\mathrm{b}}$ was generated immediately, and in a dominant position subsequently in the stirring process. 


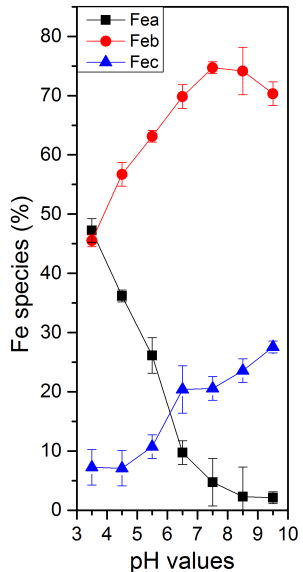

(a)

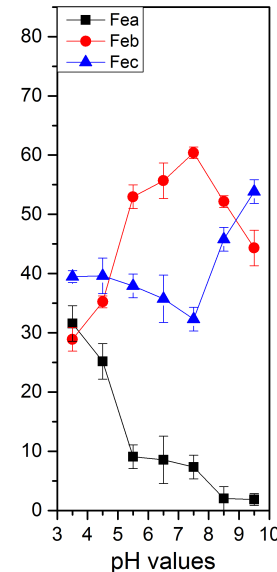

(b)

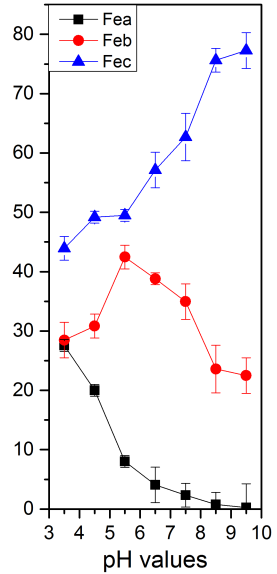

(c)

Fig. 3 Transformation of iron species under different $\mathrm{pH}$ values during the coagulation-flocculation process. (a) Rapid mixing stage, (b) Slow mixing stage, (c) settling stage.

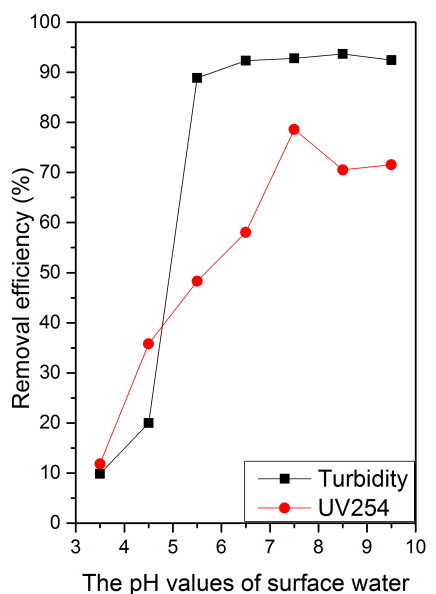

(a)

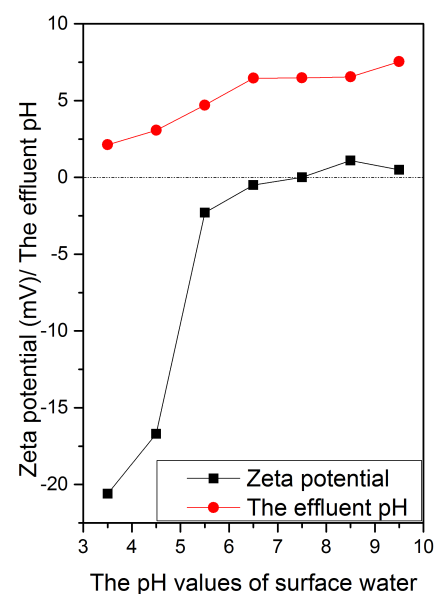

(b)

Fig.4 Effect of the $\mathrm{pH}$ value on the coagulation performance. (a) The turbidity and $\mathrm{UV}_{254}$ removal, (b)

Zeta potential of the flocs and the effluent $\mathrm{pH}$.

\section{Electrostatic Interaction between Coagulants and HA}

The initial $\mathrm{pH}$ value of treated water has been found to affect the quality of the effluent at the dosage of PFS of $54 \mathrm{mg} \mathrm{Fe} / \mathrm{L}$ (Fig.4). The removal of turbidity and $\mathrm{UV}_{254}$ increased steadily with higher $\mathrm{pH}$ in the range from 3.5 to 7.5 . Correspondingly, the variation of zeta potential ranging from 3.5 to 7.5 in Fig.4 (b) indicated the charge neutralization and compression electric double layer dominated the remove of $\mathrm{UV}_{254}$, coincide with the fact that the high-density cation charge $\mathrm{Fe}_{\mathrm{b}}$ increased steadily at the elevated $\mathrm{pH}$.

In addition to the charge neutralization, the adsorption by amorphous hydroxide precipitates formed during the coagulation process contributes to the HA removal[13]. In general, charge neutralization occurs at slightly acidic $\mathrm{pH}$, while adsorption occurs at the appearance of precipitation at high $\mathrm{pH}$ values or at high coagulant doses.

Fig. 5 (a) compares the turbidity removal differences between the whole coagulation-flocculation process and the adsorption process by iron precipitates. Because the colloidal particles in the water causing turbidity are mostly negatively charged, the iron precipitates with little charges has low removal efficiency of turbidity. At $\mathrm{pH} 5.5$, the turbidity removal efficiency reached the maximum, which was consistent with distribution of $\mathrm{Fe}$ (III) species in Fig. 3 (c) that $\mathrm{Fe}_{\mathrm{b}}$ accounted for the most at $\mathrm{pH}$ 5.5. Fig. 5 (b) compares the $\mathrm{UV}_{254}$ removal between the whole coagulation- flocculation 
process and the adsorption by iron precipitates at different $\mathrm{pH}$ conditions at the dosage of $54 \mathrm{mg} \mathrm{Fe} / \mathrm{L}$. The removal efficiency of $\mathrm{UV}_{254}$ by adsorption was $\mathrm{pH}$ dependent. At $\mathrm{pH}$ from 4 to 6 , the dominate iron species in the solution were the monomers, the adsorption capacity of these species was lower than that of the iron precipitates, which was abundant when the $\mathrm{pH}$ value exceed 6.0. With $\mathrm{pH}$ increasing from 4 to 6 , the removal of $\mathrm{HA}$ by adsorption was relatively stable. However, the $\mathrm{UV}_{254}$ removal was significantly improved at $\mathrm{pH} 7.2$, and the maximal removal efficiency of $70 \%$ was achieved.

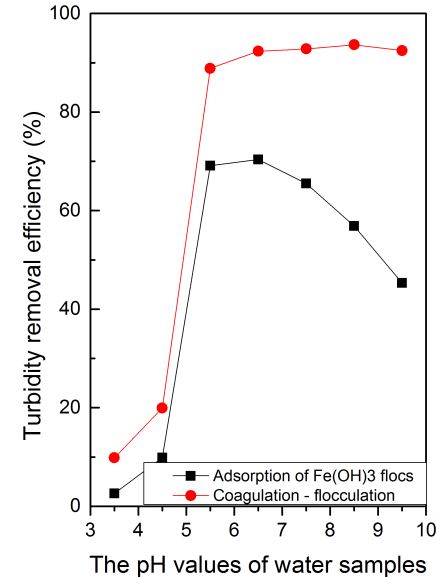

(a)

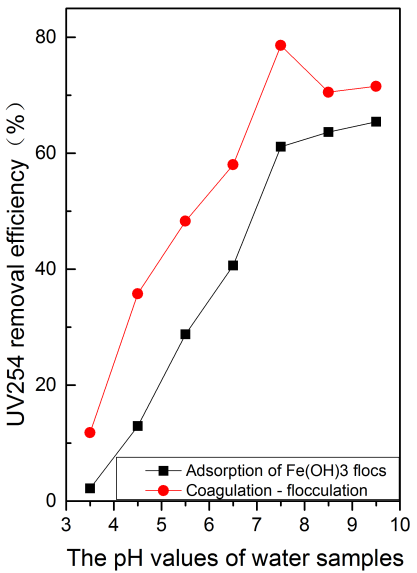

(b)

Fig. 5 Comparison of removal efficiency between coagulation-flocculation and adsorption by iron precipitates. (a) The turbidity removal efficiency, (b) The $\mathrm{UV}_{254}$ removal efficiency

\section{Conclusion}

The role of Fe (III) speciation in the coagulation of surface water by PFS was studied for the first time in this paper. The results showed that $\mathrm{Fe}_{\mathrm{b}}$ polymers were stable in the dilute solution and dominant during the stirring process at $\mathrm{pH}$ of 5.5 8.0, while the Feb is the content rich in high density cation charges. The Fe (III) speciation directly influenced the mechanisms of HA removal. The maximum removal efficiency of the $\mathrm{UV}_{254}$ was found to occur in the $\mathrm{pH}$ ranging from 7 to 8 . The changes of zeta potential explained that charge neutralization and compression electric double layer were the main mechanisms of coagulation, thus high Feb should be necessary to obtain an efficient removal of the the $\mathrm{UV}_{254}$, but adsorption and sweeping of $\mathrm{HA}$ by amorphous $\mathrm{Fe}(\mathrm{OH})_{3}$ (s) played an important role at $\mathrm{pH}>7.0$ as well.

\section{Acknowledgement}

This research was financially supported by the National Key Research and Development Program (No. 2017YFC0210200) of China.

\section{References}

[1] S.D. Richardson, Disinfection by-products and other emerging contaminants in drinking water, Trac-Trends in Analytical Chemistry 22 (2003) 666-684.

[2] Z. Yang, B. Liu, B. Gao, Y. Wang, Q. Yue, Effect of Al species in polyaluminum silicate chloride (PASiC) on its coagulation performance in humic acid-kaolin synthetic water, Separation and Purification Technology 111 (2013) 119-124.

[3] A.I. Zouboulis, P.A. Moussas, F. Vasilakou, Polyferric sulphate: preparation, characterisation and application in coagulation experiments, Journal of hazardous materials 155 (2008) 459-468. 
[4] X. Zhang, X. Wang, Q. Chen, Y. Lv, X. Han, Y. Wei, T. Xu, Batch Preparation of High Basicity Polyferric Sulfate by Hydroxide Substitution from Bipolar Membrane Electrodialysis, ACS Sustainable Chemistry \& Engineering 5 (2017) 2292-2301.

[5] H. Dong, B. Gao, Q. Yue, H. Rong, S. Sun, S. Zhao, Effect of Fe (III) species in polyferric chloride on floc properties and membrane fouling in coagulation-ultrafiltration process, Desalination 335 (2014) 102-107.

[6] W. Xu, B. Gao, Effect of shear conditions on floc properties and membrane fouling in coagulation/ultrafiltration hybrid process - The significance of Alb species, Journal of Membrane Science 415-416 (2012) 153-160.

[7] B. Gao, B. Liu, T. Chen, Q. Yue, Effect of aging period on the characteristics and coagulation behavior of polyferric chloride and polyferric chloride-polyamine composite coagulant for synthetic dying wastewater treatment, Journal of hazardous materials 187 (2011) 413-420.

[8] G. Lei, J. Ma, X. Guan, A. Song, Y. Cui, Effect of basicity on coagulation performance of polyferric chloride applied in eutrophicated raw water, Desalination 247 (2009) 518-529.

[9] Y. Wang, B. Gao, Q. Yue, J. Wei, Q. Li, The characterization and flocculation efficiency of composite flocculant iron salts-polydimethyldiallylammonium chloride, Chemical Engineering Journal 142 (2008) 175-181.

[10] B. Wang, Y. Shui, P. Liu, M. He, Preparation, characterization and flocculation performance of the inorganic-organic composite coagulant polyferric chloride and polydimethyldiallylammonium chloride, Journal of Chemical Technology \& Biotechnology 92 (2017) 884-892.

[11] P.A. Moussas, A.I. Zouboulis, Synthesis, characterization and coagulation behavior of a composite coagulation reagent by the combination of polyferric sulfate (PFS) and cationic polyelectrolyte, Separation and Purification Technology 96 (2012) 263-273.

[12] K.E. Lee, N. Morad, T.T. Teng, B.T. Poh, Development, characterization and the application of hybrid materials in coagulation/flocculation of wastewater: A review, Chemical Engineering Journal 203 (2012) 370-386.

[13] B. Shi, Q. Wei, D. Wang, Z. Zhu, H. Tang, Coagulation of humic acid: The performance of preformed and non-preformed Al species, Colloids and Surfaces A: Physicochemical and Engineering Aspects 296 (2007) 141-148. 